\title{
Study on the Influence of Foreign Direct Investment
}

\author{
on Chinese Foreign Trade
}

\author{
Mengchun Ding \& Hongxin Li \\ School of Economics and Management, Changchun University of Science and Technology, Changchun 130022, China \\ Tel: 86-431-8203-0456 E-mail: dingmengchun312@163.com
}

\begin{abstract}
Under the background that global foreign direct investment (FDI)crashed largely, Chinese foreign investments fell year on year in the first half year of 2009, but its proportion in the global FDI gross didn't drop, and China is still the first investment place for feign investments in the world. China is the country which attracted most FDI accumulatively in all developing countries and had the most amount of foreign sub-company in the world. But many problems still exist in the process that China uses FDI to improve the development of international trade. In the article, the FDI is first introduced, and the influences of FDI on Chinese foreign trade are pointed out, and the countermeasures that Chinese uses FDI to improve the development of international trade are put forward finally.
\end{abstract}

Keywords: Foreign direct investment (FDI), Imports and exports, Foreign Trade

\section{Introduction of FDI}

\subsection{Actuality of FDI in China}

FDI means the foreign investment activities that the enterprises, governments and individuals of one country invest in the industry, the agriculture and the finance and the service industry in foreign countries by various forms and obtain all or part of the management and control rights of these investment enterprises, taking the profit acquirement as the main intention. Since 1994, the proportion of foreign investment enterprises in the total amount of Chinese imports and exports rose year after year, and this number was $35.69 \%$ in $1994,57.74 \%$ in 2007 , and $59.8 \%$ in 2008 , which fully indicated that the foreign investment enterprises have occupied very important status in Chinese trade at present. To adapt the situation after China entered into WTO and opened to the world, Chinese relative departments adjusted and constitute a series of polices and laws to build more loose and transparent policy environment for multinational companies to enter into Chinese market. These policy changes mainly include broadening the sale proportion of foreign investment enterprises in Chinese market and canceling the foreign exchange balance requirement of China, further modifying the "Guiding List of Industries for Foreign Investment", issuing many laws relative to foreign mergers such as the "Using Foreign Investment to Reorganize State-owned Enterprises Tentative Provisions" and the "Merger with and Acquisition of Domestic Enterprises by Foreign Investors Tentative Provisions", and further standardizing the merger activities of multinational companies in Chinese market and improving the multiform modes that China utilizes foreign investments, issuing and implementing new policies of using foreign investments in many industries such as the finance, the telecom and the railway, which created advantages for the service industry to utilize the foreign investments. At the same time, to support the manufacturing of multinational companies transferring to China and welcoming the time of "Made in China", various local governments obviously strengthened the policy construction in integrating local resources and optimizing investment environment, and gradually modified their policies to adapt the introduction of foreign investments.

\subsection{Effect of FDI on international trade}

\subsubsection{Trade substitution effect}

One commodity can enter into the market of other country by two modes such as the trade and investment, and when the investment is selected, the trade will be substituted. Especially in the situation that two countries have same or similar technologies, as the result of the gradual course of company internationalization (from trade to FDI), FDI and trade can be substituted each other for special products in the manufacturing. The internationalization of many manufacturing multinational companies all presented by the process from exports to establishing the trade company in foreign countries and then establishing international production and management system by FDI, so the subsequent investments will certainly substitute the former trade.

\subsubsection{Trade creation effect}

FDI can create new trade opportunities between home country and host country, and make the trade be made in larger scale. FDI will directly induce the exports of capital products, medium investment, technology and service, and improve 
the trade of home country. Especially, as the transfer of advanced production technology, FDI will reduce the costs, enhance the efficiency and improve the multinational flow of information, so for a long time, FDI will create new demand of trade, and drive the export trade from host country to home country.

\subsubsection{Market expansion effect}

The production expansion realized by FDI will not only deepen the market infiltration to host country, but further develop new third country's market, and accordingly make the production oriented by the trade to bring the increase of total trade.

In different stages of the special FDI project, above four effects will occur alternately. In the initial stage of the project, because the imports of the capital products and medium investment, the trade creation effects making for home country will occur sometimes. As the production goes along, the trade substitution effect will gradually occur. And the subsequent successful management will bring the trade compensation effect and the market expansion effect. Therefore, the review of FDI trade effect should be observed in a long time.

\section{Influences of FDI on Chinese foreign trade}

\subsection{FDI can significantly improve the structure of Chinese export products}

More and more multinational companies begin to directly invest in China by large scale, which makes the market structure of Chinese foreign trade to be improved significantly. The dispersal of risks strengthens the emergency meeting ability and releases the actuality that Chinese export markets are too centralized, which will help to implement the multi-culture strategy of exports and adapt the demands of Chinese foreign expansion. FDI can mainly drive the exports of labor and resource centralized industrial products. The essential intention that FDI swarms into China is to develop its own markets abroad by using the manufacturing base, China. Most multinational companies utilize the competitive advantages in capitals, technologies and marketing management to combine their capitals and technologies with Chinese cheap labor resources and material resources to largely develop the trade of export manufacturing, so they can certainly be in the dominant status in the export competition with Chinese non-foreign investment enterprises.

\subsection{FDI can compensate the shortage of the production agent of China, and offer necessary material supplements for the imports and exports}

The export trade is mainly restrained by the domestic production agent and influenced by the world market factor. As a developing country, China is restrained by the deficient capitals and technologies for a long time. The flow-in of FDI can largely increase the supply of Chinese production agent, improve the allocation of production resources, and expand the production ability. Most FDI enterprises in China came from Japan, Korea, US, European Union and countries in Southeast Asia. In these countries, the contents and layers of capitals and technologies in developed countries are relatively higher, but the technology-dense degree and layer of newly industrializing countries such as Korea and Singapore are lower. As viewed from the investment scale, the enterprises with large scale came from US and European Union, but the proportion of investment is relatively lower. In Japan and Korea, most FDI enterprises are middle and small-sized enterprises which belong to labor-dense type from the industry orientation, and these enterprises respectively belong to the industries such as food making, fabrics, shoes, toys, bicycle and container, and few of them belong to the capital-dense and technology-dense industries.

\subsection{The technical overflow effect and the market entrance overflow existing in FDI enterprises can drive the development of the exports for Chinese domestic enterprises}

By the association with FDI, domestic enterprises can acquire more information about international market, better establish relation with foreign groups, share the result of free trade with FDI enterprises, reduce the obstacles with the foreign market, and improve the export trade by the information, sales channel and distribution service of FDI. Through the transfer and diffusion of capitals, technologies, management and technology, FDI can enhance the ability of production and export for China, and its indirect trade effect will finally improve the development of Chinese export.

\subsection{FDI will negatively influence the balance of payments of China}

Another problem concealed in promoting foreign trade effect of foreign investment is that the over-quick increase of imports of foreign enterprises and the gradual increase of remitted profit of foreign funded enterprises entering into the mature stage will bring pressures for the international balance of payments. The main reasons of too-quick imports of foreign funded enterprises include following points. First, large numerous of foreign-funded enterprises depend on the imports too much, and quite part products are sold in domestic market but not in foreign countries. Second, the imports of the non-industrial enterprises increase too quickly. Third, the import costs of "foreign funded enterprises" in individual industries such as the car manufacturing, the air-conditioner manufacturing and the thermal power generation are too higher, and the trade deficient of foreign exchange is obvious. Fourth, the import management of second-hand equipments which belong to the practicality investment from the country to the foreign funded enterprises is not perfect, which not only increase the low-efficiency imports, but influence the exports of products with high additive values. 
Starting from the corresponding relation between imports and exports, above factors will not only influence the trade balance, but restrain the enhancement of the export quality.

\section{Using FDI to improve the development countermeasures of Chinese foreign trade}

3.1 Further building stable and transparent policy environment, uniform and opening market environment and standard and high-efficient administration environment for foreign investments

Chinese governments on various levels should perfect various regulations and management systems, constitute uniform and transparent policies, standardize the authorization procedures to adapt the demand that China enters into WTO, further strengthen the guidance for the foreign investments, encourage foreign investments to flow to newly high-technical industries, adopt measures to promote the introductions of new technology and products, encourage the $R \& D$ of foreign invested enterprises in China to enhance the technical content of export products.

\subsection{Enhancing the quality level of FDI and transform FDI guidance mode to improve the updating of industries}

On the base that the government fully exerts the existing comparison advantage, the government should quickly enhance the international competitive force of export industries by many approaches such as technical innovation, system innovation and structure innovation. It is possible to introduce new technologies in the development mode of competition advantage. First, the biggest advantage that undeveloped countries perform the strategy of new-technical orientation is that they have no deposited costs. Second, undeveloped countries can absorb the experiences and trainings of developed countries about the development of relative industries. The development of modern information network economy has broken the rules of industrial economy (grads development) to quite large extent, and eliminated the traditional space and time distance restraining the economic development to some extents, so if the new industries developed by the home country are defined as the new world industries, the span-development of industrial updating will be realized, and the industrial level will be quickly enhanced.

\subsection{Strengthening the supervision on foreign trade behaviors of foreign invested enterprises}

Quite parts of foreign funded enterprises made the feints of loss or few profit by transferring the price to escape the taxation. So it is very necessary to build a perfect supervision institution system. Many government functional departments such as the foreign economy and trade committee, foreign exchange administration, industry and commerce administration, taxation administration, commodity inspection and custom and many social agents such as accounting, auditing, asset evaluation and credit evaluation should have the functions and obligations to supervise foreign funded enterprises. To strengthen the validity supervising foreign funded enterprise, above various departments should increase associations, confirm their own functions and form an organic system, enhance the service efficiency of governmental departments, eliminate obstructions among them to make the supervision of foreign funded enterprises form an associated linkage mechanism with good management efficiency.

3.4 Leading domestic enterprises to enter into the global production system and drive the updating of exports by the multinational companies

As the matching rate of foreign funded enterprises rises, many domestic enterprises begin to enter into the global production system of multinational company. Chinese enterprises should actively grasp the opportunity of international industrial transfer, especially continually strengthen the cooperation with multinational companies, participate in the international division and competition, and realize the updating of the technical and industrial structure. Multinational companies are the leaders of global technical innovation, and their productions all over the world powerfully promote the diffusion of technologies, so to attract the investment of multinational companies is the important measure to acquire global knowledge and technology and the important approach to reduce the gap between China and developed countries in knowledge, technology and management. According to the development tendency of world economy and the capital-attraction experiences since China has opened to the world for thirty years, in the present and future terms, China should continually attract the investments of world top 500 enterprises as the emphasis and breakthrough inviting investments from overseas. One of directions guiding foreign investments is to make more Chinese enterprises enter into the global production and service network system by multiform association modes with foreign investment enterprises. In this network system, foreign investment enterprises can be the local agent institutions of the global production and service system, and make the local enterprises to be in line with the world and grow to be world components manufacturers or service suppliers.

\subsection{Supporting the development of FDI in the service industry and improving the development of Chinese international service trade}

At present, many problems such as the lagged development of the service industry, the undeveloped marketization and opening degree, weak international competition force of the service industry and seriously lagged laws and management about the international service trade still exist in the international service trade of China, and these problems have seriously restrained the development of Chinese exports of service trade. According to the promise to the General 
Agreement on Trade in Services (GAST), China will gradually open its service trades. GAST emphasized the participation degree of developing countries to the world service trade and expanded their service exports, which is very useful for the development of Chinese service industry. However, many industries such as finance and telecom will influence the whole economic situation of China, so they should not be opened blindly. Therefore, various service industries should seriously research the promises when China entered into WTO, gradually guild the investments of FDI enterprises and open the market of service trade, develop the industries with dominant advantages to go to the international market, participate in the international competition, and expand the exports of service trade.

\section{References}

He, Qingguang. (2008). On the Dynamic Effects of Foreign Direct Investment on China's Economic Growth. Economic and Social Development. No.12.

Li, Hao. (2008). New Trend of FDI in the World and New Characteristics of Utilizing Foreign Capital. Forum of World Economy \& Politics. No.1.

Wang, Shouyang et al. (2007). Analysis and Prediction of the Situation that China Uses FDI in 2007. China Trade News. No.1. 